Given the very low rates of correct responses at baseline regarding predictors of fibrosing ILD and assessing prognosis, it will be important to continue to reinforce these learnings in ongoing educational programs.

Conclusion: This study demonstrates the success of segmented online education in improving rheumatologists' and pulmonologists' knowledge and competence in evaluating risk and prognosis of fibrosing ILD and managing patients with CTDILDs. This could lead to earlier changes in therapeutic approach for those with signs of progression and result in improved overall outcomes for these patients.

REFERENCES

[1]Kolb M, Maher T, Smith V, Jacob J, Rimekasten G. Catching and Managing Progressive Fibrosing Interstitial Lung Disease Progression Earlier. Launched: Oct 9, 2020. Data as of Dec 18, 2020. Available at www.medscape.org/viewarticle/938826

Disclosure of Interests: Christy Rohani-Montez: None declared, Marinella Calle: None declared, Chris Allen: None declared, Toby Maher Speakers bureau: Astra Zeneca, Bayer, Blade Therapeutics, Boehringer Ingelheim, Bristol-Myers Squibb, Galapagos, Galecto, GlaxoSmithKline R\&D, Indalo, IQVIA, Pliant, Respivant Roche and Theravance, Consultant of: Astra Zeneca, Bayer, Blade Therapeutics, Boehringer Ingelheim, Bristol-Myers Squibb, Galapagos, Galecto, GlaxoSmithKline R\&D, Indalo, IQVIA, Pliant, Respivant, Roche and Theravance, Grant/research support from: Astra Zeneca and GlaxoSmithKline R\&D, Vanessa Smith Speakers bureau: Boehringer-Ingelheim Pharma GmbH\&Co and Janssen-Cilag NV, Consultant of: Boehringer-Ingelheim Pharma GmbH\&Co, Grant/research support from: Research Foundation - Flanders (FWO), Belgian Fund for Scientific Research in Rheumatic diseases (FWRO), Boehringer-Ingelheim, Pharma GmbH\&Co, and Janssen-Cilag NV, Joseph Jacob Speakers bureau: Boehringer-Ingelheim; Roche Consultant of: Boehringer-Ingelheim, Grant/research support from: GlaxoSmithKline, Gabriela Riemekasten Speakers bureau: AbbVie; Actelion; Boehringer-Ingelheim, Consultant of: Actelion; CellTrend; Janssen, Grant/research support from AbbVie; Actelion, Martin Kolb Speakers bureau: AstraZeneca; Boehringer-Ingelheim; Novartis; Roche, Consultant of:AbbVie Inc.;Algernon Pharma;AstraZeneca; Boehringer-Ingelheim; Cipla; Covance; EPG Health; Galapagos NV; Gilead; GlaxoSmithKline; Indalo; Mitolmmune Therapeutics Inc; Novartis; Pieris; Prometic (now Liminal Biosciences); Roche; Third Pole Inc.; TwoXAR Inc., Grant/research support from: Boehringer-Ingelheim; GlaxoSmithKline; Novartis; Prometic; Roche; Avalyn DOI: 10.1136/annrheumdis-2021-eular.1510

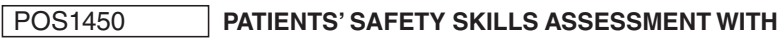 BIOLOGICS AND JAK INHIBITORS: UPDATE OF THE BIOSECURE QUESTIONNAIRE}

C. Beauvais $^{1}$, V. Gaud-Listrat ${ }^{2}$, J. Sellam ${ }^{3}$, F. Fayet ${ }^{4}$, M. Beranger ${ }^{5}$, N. Deparis ${ }^{6}$ M. Antignac ${ }^{7}$, C. Sordet ${ }^{8}$, M. Rodere ${ }^{4}$, L. Gossec ${ }^{9}$ on behalf of On the behalf of the therapeutic patient education section of the French Rheumatology Society. ${ }^{1}$ Centre Hospitalier Universitaire Saint Antoine, Sorbonne Université, Rheumatology Department, Paris, France; ${ }^{2}$ Cochin Hospital, Rheumatology Department, Paris, France; ${ }^{3}$ Hospital Saint-Antoine Ap-Hp, Rheumatology Department, Paris, France; ${ }^{4}$ Centre Hospitalier Universitaire Gabriel Montpied, Rheumatology Department, Clermont-Ferrand, France; ${ }^{5}$ Centre Hospitalier Universitaire Orléans, Rheumatology Department, Orleans, France; ${ }^{6}$ Association Nationale de Défense Contre l'Arthrite Rhumato ïde, ANDAR, Paris, France $;{ }^{7}$ Centre Hospitalier Universitaire Saint Antoine, Sorbonne Université APHP, Pharmacy Department, Paris, France; ${ }^{8}$ Hôpitaux Universitaires de Strasbourg, Rheumatology Department, Strasbourg, France; ${ }^{9}$ Sorbonne Université, Hopital Pitié Salpetrière, Rheumatology Department, Paris, France

Background: Biologic disease-modifying anti-rheumatic drug (bDMARDs) and JAK inhibitors (JAKi) may lead to an increased risk of infections, which could be prevented by enhancing patients' safety skills (ref). We developed a self-administered questionnaire (BioSecure1, ref) in 2013 to assess the patients' safety skills (Table 1). Following the appearance of new bDMARDs and JAKi and new information on safety, this questionnaire needed updating.

Table 1. Nine domains of core safety skills and number of corresponding questions in BioSecure questionnaires.

\begin{tabular}{lcc}
\hline Domain of competence & BioSecure1 & BioSecure2 \\
\hline General knowledge & 4 & 2 \\
Dealing with infectious symptoms and fever & 10 & 11 \\
$\begin{array}{l}\text { Dealing with other infectious symptoms } \\
\text { Dealing with injuries, preventing infectious complications, }\end{array}$ & 4 & 4 \\
$\quad$ vaccinations & 8 & 8 \\
$\begin{array}{l}\text { Dental hygiene, preventing infectious complications, information to } \\
\quad \text { share with the dentist }\end{array}$ & 2 & 2 \\
$\begin{array}{l}\text { Planning surgery, information to share with the surgeon/ } \\
\quad \text { anesthesiologist }\end{array}$ & 7 & 7 \\
$\begin{array}{l}\text { Planning child conception } \\
\text { Communication: who to contact? }\end{array} \quad 2$ & 1 \\
$\quad \begin{array}{l}\text { Subcutaneous treatments: cold chain/cold storage, subcutaneous } \\
\quad \text { injection techniques }\end{array}$ & 2 & 2 \\
\end{tabular}

Objectives: To update the BioSecure questionnaire assessing patients' safety skills

Methods: Four steps by a 10 participants multidisciplinary steering committee. Step 1: critical analysis of content and formulations of BioSecure1 on the basis of i) the participants' own experience of the questionnaire use in current practice (5/10 participants) or research (6/10 participants) ii) assessment of BioSecure 1 consistency with current guidelines for management of targeted drugs. Step2: development of a first updated version by a core group of 10 persons. Step3: comments by an extended panel of rheumatology teams interested in therapeutic patient education (TPE). Step4: testing of the final version (Biosecure2) by ten patients through cognitive debriefing.

Results: In total, 10 rheumatologists, 6 rheumatology nurses, 1 pharmacist and 1 patient from a patient association participated. Inadequate formulations were reported regarding some situations for which recommendations had the most shifted since Biosecure1 development such as planning pregnancy, remission management and prevention measures before surgery. Features of some infectious conditions were clarified; barriers measures against infection and complications such as sigmoiditis and Herpes Zoster infection were added BioSecure 2 continues to assess the 9 domains of core safety skills (Table 1 ) The questionnaire was shortened to 50 items (mean filling in time is 10 min utes) with a good understanding and scoring was simplified (mean scoring time 3.5 minutes)

Conclusion: BioSecure2 represents an updated outcome measure to evaluate the patient's skills to prevent adverse events with targeted therapies. This questionnaire can be useful in the context of patient-health professional communication, and as a tool to measure TPE on safety issues.

REFERENCES:

[1] Gossec et al, Joint Bone Spine. 2013;80:471-476

Disclosure of Interests: None declared

DOI: 10.1136/annrheumdis-2021-eular.1628

\section{POS1451 DEVELOPING A TOOL TO MEASURE THE LEARNING CURVE: ENTHESITIS ULTRASOUND IN PSORIASIS ARTHRITIS}

S. Brådland ${ }^{1}, \underline{\text { P. Andel }}{ }^{1,2,3}$, A. Diamandopoulos ${ }^{4,5}$, G. Haugeberg ${ }^{1,6} .{ }^{1}$ Hospital of Southern Norway, Department of Rheumatology, Kristiansand, Norway; ${ }^{2}$ Østfold Hospital Trust, Department of Cardiology, Kalnes, Norway; ${ }^{3}$ University of Oslo, Department of Clinical Medicine, Oslo, Norway; ${ }^{4}$ Akershus University Hospital, Department of Rheumatology, Oslo, Norway; ${ }^{5}$ Martina Hansens Hospital, Department of Rheumatology, Bærum, Norway; ${ }^{6}$ Norwegian University of Science and Technology, Department of Neuromedicine and Movement Science, Faculty of Medicine and Health Sciences, Trondheim, Norway

Background: Enthesitis is defined as inflammation of the tendon inserting the bone encompassing the adjacent trabecular bone network, the fascia and surrounding soft tissues as the cartilage, the bursa and the fat pad. In enthesitis clinical examination alone is a method with significant limitations in terms of diagnostic accuracy and does not correlate strongly with imaging diagnostics $(1,2)$

Ultrasound (US) is a widely used imaging technique in Rheumatology. But while learning curricula and standardization for joint US are available, other US techniques as vascular-, enthesis- or serosa-US gets usually less attention in rheumatologic US curricula. Though both OMERACT (4) and GRAPPA (3) have recently published qualitative and semi quantitative criteria in enthesitis US, few publications explicitly address the learning curves in these particular domain.

Objectives: To describe the development of a tool to measure the learning curve for enthesitis US.

Methods: 3237 US images of 561 enthesis were obtained by one experienced ultrasonographer (PMA) in B- and color Doppler (CD) mode in longstanding psoriasis arthritis patients of different disease activity. Due to duplicity and poorer image quality 2115 images were eliminated. The remaining fully anonymized 1122 images (561 enthesis) were afterward implemented in a random multiple choice algorithm presenting a B-mode and a CD image of the same enthesis at the same time without timely limitation. Rating follows qualitative GRAPPA criteria as well as semiquantitative OMERACT criteria $(3,4)$. The enthesitis scoring application was than written in.NET/ C\#, TypeScript and ReactJS and is hosted in Azure Cloud platform. The scoring is stored in a database allowing extraction to SPSS for statistical analysis.

Results: The interface of the functional program is shown in image 1 (Screenshot). In a next step the program will be presented to different raters of different ultrasound experience (>10 years, 5-10 years, $1-5$ years, $<1$ years). The program will be presented a multitude of times in different order to every rater to adjust for inter-rater reliability. Correlation between raters will be given to depict a learning curve on enthesitis ultrasound assuming the rater with the highest experience as gold standard. 


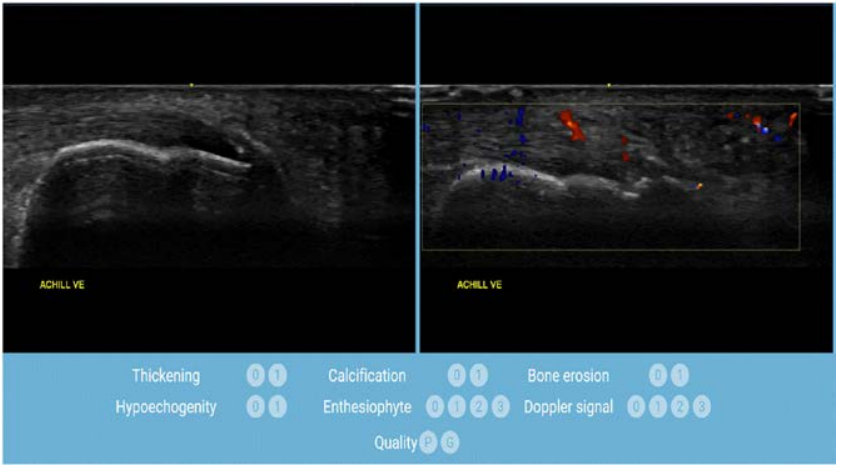

Image 1. Screenshot of grafical user interface of the scoring program.

Conclusion: In this presentation we outline the successful development of a tool to measure the learning curve in enthesitis. We hypothesize that knowledge about the learning curve and inter-rater reliability in enthesitis US obtained by our tool might contribute to future US curricula, structured reporting and deep learning algorithms.

REFERENCES:

[1] Achilles enthesitis defined by ultrasound is not associated with clinical enthesitis in patients with psoriatic arthritis, Brigitte Michelsen et al. RMD Open 2017;3

[2] Ultrasonographic evaluation in psoriatic arthritis is of major importance in evaluating disease activity Brigitte Michelsen et al. Annals of the Rheumatic Diseases 12(2108-2113)

[3] Development of a Preliminary Ultrasonographic Enthesitis Score in Psoriatic Arthritis -GRAPPA Ultrasound Working Group, Stephanie Tom et al. The Journal of Rheumatology; 4(384-390)

[4] Reliability of a consensus-based ultrasound definition and scoring for enthesitis in spondyloarthritis and psoriatic arthritis: an OMERACT US initiative, Peter V Balint et al. Annals of the Rheumatic Diseases, 12(1730-1735)

Disclosure of Interests: None declared

DOI: 10.1136/annrheumdis-2021-eular.4096

\section{Educational cases}

\section{POS1452 DE NOVO LUPUS NEPHRITIS FOLLOWING THE INTRODUCTION OF BELIMUMAB}

J. Pinnell ${ }^{1}$, S. Tosounidou' ${ }^{1}{ }^{1}$ Birmingham City Hospital, Rheumatology, Birmingham, United Kingdom

Background: Belimumab inhibits the activity of the soluble cytokine BLyS (B lymphocyte stimulator) and is recommended for use in moderate refractory systemic lupus erythematosus (SLE). A recent randomised controlled trial reported that Belimumab improves the outcomes for patients with lupus nephritis when used with standard therapy.

Objectives: We present two cases of lupus nephritis that developed in SLE patients without pre-existing renal disease shortly after commencing treatment with Belimumab.

Methods: Both patients are Afro-Caribbean females with similar immunological profiles, including ANA, dsDNA, anti-Sm, anti- Ro and anti-RNP antibodies. The first was 59 years old with a long standing diagnosis of SLE since 1996 that had required previous Cyclophosphamide for neuropsychiatric lupus. She was most recently taking Hydroxychloroquine, Mycophenolate and Prednisolone having previously failed with Azathioprine twice. Belimumab was commenced in February 2020 due to worsening arthritis, mouth ulcers, pleuritis and systemic features associated with a significant rise in her dsDNA and low complement. Her SLEDAl score was 13. After six months of treatment she developed proteinuria for the first time. Her urine protein creatinine ratio (UPCR) was measured at $205 \mathrm{mg} /$ $\mathrm{mmol}$ and a subsequent renal biopsy revealed features of active Class IV and $\mathrm{V}$ lupus nephritis. Belimumab was changed to Rituximab. Mycophenolate was stopped due to persistent neutropenia and Tacrolimus was introduced instead. After 5 months treatment her uPCR is now $33 \mathrm{mg} / \mathrm{mmol}$.

The second patient was 37 years old with a recent diagnosis of SLE in 2018. She presented with inflammatory arthritis, oral and nasal ulcers, and cytopenia. She responded poorly to Azathioprine and was intolerant of Mycophenolate. Her most recent treatment was Hydroxychloroquine and Prednisolone. She was commenced on Belimumab in February 2020 due to active mucocutaneous and musculoskeletal features of lupus with a SLEDAI score of 12 . The mucocutaneous features of lupus responded well but she developed proteinuria seven months later, and by November 2020 her uPCR was $149 \mathrm{mg} / \mathrm{mmol}$. Belimumab was switched to Rituximab and initially her UPCR continued to rise but it has now fallen to $43 \mathrm{mg} / \mathrm{mmol}$

Results: The occurrence of new lupus nephritis soon after the initiation of Belimumab monotherapy has been reported previously and our cases raise further concerns. A prospective observational study recently reported significantly increased rates of new lupus nephritis developing in patients receiving Belimumab in addition to standard care compared to those receiving standard treatment. An association between Belimumab and the development of de novo lupus nephritis has not yet been conclusively established but it would create a significant challenge in how Belimumab is used and consented for in SLE, especially if it becomes more widely used to treat lupus nephritis. The mechanism by which Belimumab may increase the risk of, or trigger, lupus nephritis is currently unclear but may result from increased activity in BLyS associated pathways following the blockade of the BLyS pathway.

Conclusion: These two cases raise questions about the role of using Belimumab in patients at risk of developing lupus nephritis. We therefore recommend caution in its use and recommend active monitoring of renal parameters especially in patients with poor clinical and serological response to Belimumab. REFERENCES:

[1] Furie R, Rovin BH, Houssiau F, et al. Two-year, randomized, controlled trial of belimumab in lupus nephritis. N Engl J Med. 2020; 383(12):1117-28

[2] Sjöwall C, Cöster L. Belimumab may not prevent lupus nephritis in serologically active patients with ongoing non-renal disease activity. Scand J Rheumatol. 2014; 43(5):428-30

[3] Staveri C, Karokis D, Liossis SN. New onset of lupus nephritis in two patients with SLE shortly after initiation of treatment with belimumab. Semin Arthritis Rheum. 2017; 46(6):788-790

[4] Parodis I, Vital EM, Hassan SU, et al. De novo lupus nephritis during treatment with belimumab. Rheumatology. 2020; keaa796

Disclosure of Interests: None declared

DOI: 10.1136/annrheumdis-2021-eular.67

\begin{tabular}{|l|l}
\hline POS1453 & OVERLAPPING FEATURES OF RELAPSING \\
POLYCHONDRITIS AND SWEET'S SYNDROME: \\
COULD THIS BE VEXAS (VACUOLES, UBIQUITIN \\
A1E MUTATION, X-LINKED, AUTOINFLAMMATORY, \\
SOMATIC) SYNDROME?
\end{tabular}

A. Vivekanantham ${ }^{1,2}$, M. Kesavan ${ }^{3}$, J. Evans ${ }^{4}$, R. N. Matin ${ }^{5}$, I. Elliott ${ }^{6}$, R. Luqmani ${ }^{1,2} .{ }^{1}$ Oxford University Hospitals NHS Foundation Trust, Nuffield Orthopaedic Centre, Rheumatology, Oxford, United Kingdom; ${ }^{2}$ University of Oxford, Nuffield Department of Orthopaedics, Rheumatology and Musculoskeletal Sciences, Botnar Research Centre, Oxford, United Kingdom ${ }^{3}$ Oxford University Hospitals NHS Foundation Trust, Churchill Hospital, Haematology, Oxford, United Kingdom; ${ }^{4}$ Oxford University Hospitals NHS Foundation Trust, Churchill Hospital, Haematology, Oxford, United Kingdom; ${ }^{5}$ Oxford University Hospitals NHS Foundation Trust, Churchill Hospital, Dermatology, Oxford, United Kingdom; ${ }^{6}$ Oxford University Hospitals NHS Foundation Trust, John Radcliffe Hospital, Infectious Diseases, Oxford, United Kingdom

Background: An 83-year-old male presented to the infectious diseases team with intermittent fevers associated with tension headaches, malaise and fatigue for two years, with recent worsening. He had noted a progressive decline in his mobility over the past year following replacement of his right knee for osteoarthritis. His past medical history included atopic eczema, malaria and bilateral cataract extractions.

On examination, he had a widespread non-scaly annular urticated rash. He had persistently raised inflammatory markers (CRP 40mg/L, ESR $82 \mathrm{~mm} /$ hour) normocytic anaemia (Hb 102 g/L, MCV $101.9 \mathrm{fL})$, lymphopenia (0.70 x10^9/L), fluctuating eosinophilia $\left(0.88-1.25 \times 10^{\wedge} \mathrm{g} / \mathrm{L}\right)$ and a mildly elevated lactate dehydrogenase (243IU/L). A thorough work up for pyrexia of unknown origin showed no evidence of infection/ vasculitis/ immune pathology. The only positive finding was prior exposure to schistosomiasis, treated with a single dose of praziquantel. An echocardiogram and serial PET-CT scans were normal. Given the deterioration in mobility since the right knee replacement, an MRI knee was performed and cobalt/ chromium levels to look for allergic responses to the prosthesis, but these tests did not reveal any findings of significance.

An initial haematology work-up did not identify an abnormality of concern (screening for a myeloproliferative neoplasm including BCR-ABL studies were negative and mast cell tryptase was not elevated). Due to a worsening skin rash, he was reviewed by dermatology where a skin biopsy showed features of superficial neutrophilic dermatosis which can be observed with Sweet's syndrome. However, it was felt that this was an unlikely explanation for the persistent systemic symptoms. He proceeded to a bone marrow biopsy which showed reactive features including vacuolation of myeloid precursors with normal cytogenics. 